\title{
СИСТЕМЫ SMARTСITY - КАК МАГИСТРАЛЬНЫЙ ФАКТОР ИННОВАЦИОННОГО РАЗВИТИЯ РЕГИОНОВ В УСЛОВИЯХ РАСТУЩЕЙ УРБАНИЗАЦИИ
}

\section{SMARTCITY SYSTEMS AS A MAJOR FACTOR OF INNOVATIVE DEVELOPMENT OF REGIONS IN THE CONDITIONS OF GROWING URBANIZATION}

O. Gulyaeva

T. Xenofontova

Summary. The article deals with the growth of the rate of urbanization of the population in the context of a pandemic. The digital transformation of the economy and the rapid growth of urban areas have led to certain difficulties in the management of municipalities. In this context, the integration of digital technologies into management processes directly affects the degree of efficiency of city management, including in the aspect of creating a comfortable local environment. The article examines the influence of network communities on the level of management quality in large agglomerations. Ensuring the necessary decent quality of life for residents of agglomerations requires the modernization of existing urban management systems and the introduction of smart technologies in the region. The article proposes recommendations for involving residents of large agglomerations in the process of managing the development of an urban area using smart technologies.

Keywords: smart technologies, city-management, digital transformation of the urban environment, the level of quality of life, network interaction, large agglomerations, intellectualization of cities.

B условиях формирования безопасной комфортной городской среды интеграция в управленческие процессы цифровых технологий особенно актуальна, ввиду роста темпов урбанизации населения. Внедрение систем SmartCity в городах должно не навредить интересам горожан. Быстро растущая урбанизация приводит к глобальным изменениям города. Человек- ключевой элемент городской среды. Уровень урбанизации в регионах страны в 2019 г. представлен на рисунке 1.

В 2021 году возросла потребность в сетевой логике, а стремительное проникновение интернет-технологий во все социально-экономические системы привело к формированию нового мироустройства, при котором
Гуляева Ольга Анатольевна

К.э.н., дочент, Петербургский государственный университет путей сообщения Императора

Александра I

Ксенофонтова Татьяна Юрьевна

Д.э.н., профессор, Петербургский государственный университет путей сообщения Императора

Александра I

tyuksenofontova@mail.ru

Аннотация. В статье рассматриваются вопросы роста темпов урбанизации населения в условиях пандемии. Цифровая трансформация экономики и стремительный рост территорий городов обусловили определенные трудности в области управления муниципальными образованиями. В данном контексте интеграция в управленческие процессы цифровых технологий напрямую влияет на степень эффективности city-менеджмента, в том числе в аспекте формирования комфортной локальной среды. В статье рассматривается влияние сетевых сообществ на уровень качества управления крупными агломерациями. Обеспечение необходимого достойного уровня качества жизни жителей агломераций требует модернизации существующих систем управления городским хозяйством, интеллектуализации городов и внедрения смарт-технологий в регионе. В статье предложены рекомендации по вовлечению жителей крупных агломераций в процесс управления развитием городской территории использованием смарт-технологий.

Ключевые слова: смарт-технологии, city-менеджмент, цифровая трансформация городской среды, уровень качества жизни, сетевое взаимодействие, крупные агломерации, интеллектуализация городов.

сетевые структуры взаимодействия становятся основой общественно-экономической организации. Для технологий управления инновационного типа сетевая форма организации становится способом адаптации отдельных видов социальной практики. В условиях постоянно растущей конкуренции изменяются стиль и методы управления, опирающиеся не только на рост объема информации, но и на рост ее ценности $[1,10]$.

Стремительный рост агломераций, как в территориальном плане, так и в плане численности их населения, обусловил определенные трудности в осуществлении эффективного управления городским пространством. Распределение численности населения крупных городов в 2018, 2019 гг. представлено на рисунке 2. 


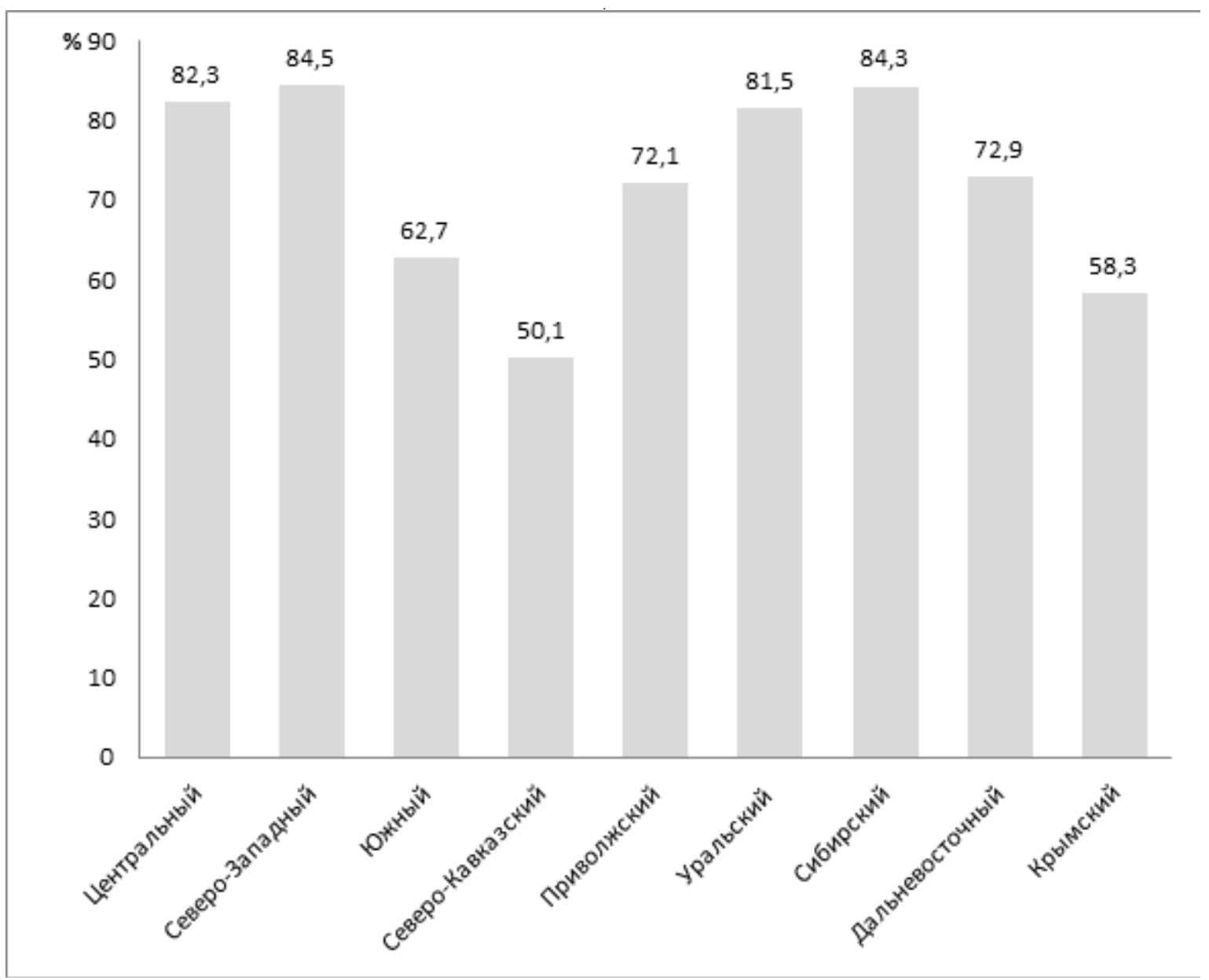

Рис. 1. Распределение уровня урбанизации в федеральных округах РФ в 2019 г.

Деятельность органов муниципальной власти, направленная на поиск путей повышения эффективности использования региональной инфраструктуры, в аспекте всеобщей диджитализации тесно связана с понятием сетевизации [2]. «Сетевизация - это инновационный тип управления, при котором одной из главных является цель интеграции органов местного самоуправления в вертикаль власти».

Сегодня в 2021 году в условиях пандемии, появляются виртуальные локальные интернет-сообщества, характеризующиеся тем, что основной целью участников таких сообществ является решение каких-либо проблем конкретной локальной территории в рамках муниципального образования. Стоит отметить, что в таком виртуальном коммуникационном поле люди, обладающие наибольшей инициативностью, привлекательностью, коммуникабельностью и уровнем соучастия имеют значительное влияние на других участников конкретных сетевых сообществ, что в дальнейшем позволяет таким людям с большей долей вероятности обрести ту или иную политическую власть [3].
Участие сетевых сообществ в формировании разнонаправленных социальных связей в сфере управления муниципальными образованиями, положительно сказывается на уровне доверия, как среди граждан, так и между жителями и органами власти. Локальные интернет-сообщества жителей города также позитивно влияют на качество построения вертикальных социальных связей, путём развития способов подотчетности, как отдельных муниципальных чиновников, так и муниципальных органов власти в целом перед гражданами.

Сетевые сообщества определяют будущее региона, становятся участниками обсуждения программ стратегического развития. Сообщества определяют требования к городской инфраструктуре, вносят предложения по изменению социально-экономических практик, распространяют информацию об актуальных проблемах жителей агломераций в онлайн-форумах.

Цифровая трансформация управленческих процессов в крупных агломерациях стала определяющим трендом в модернизации системы государственно- 


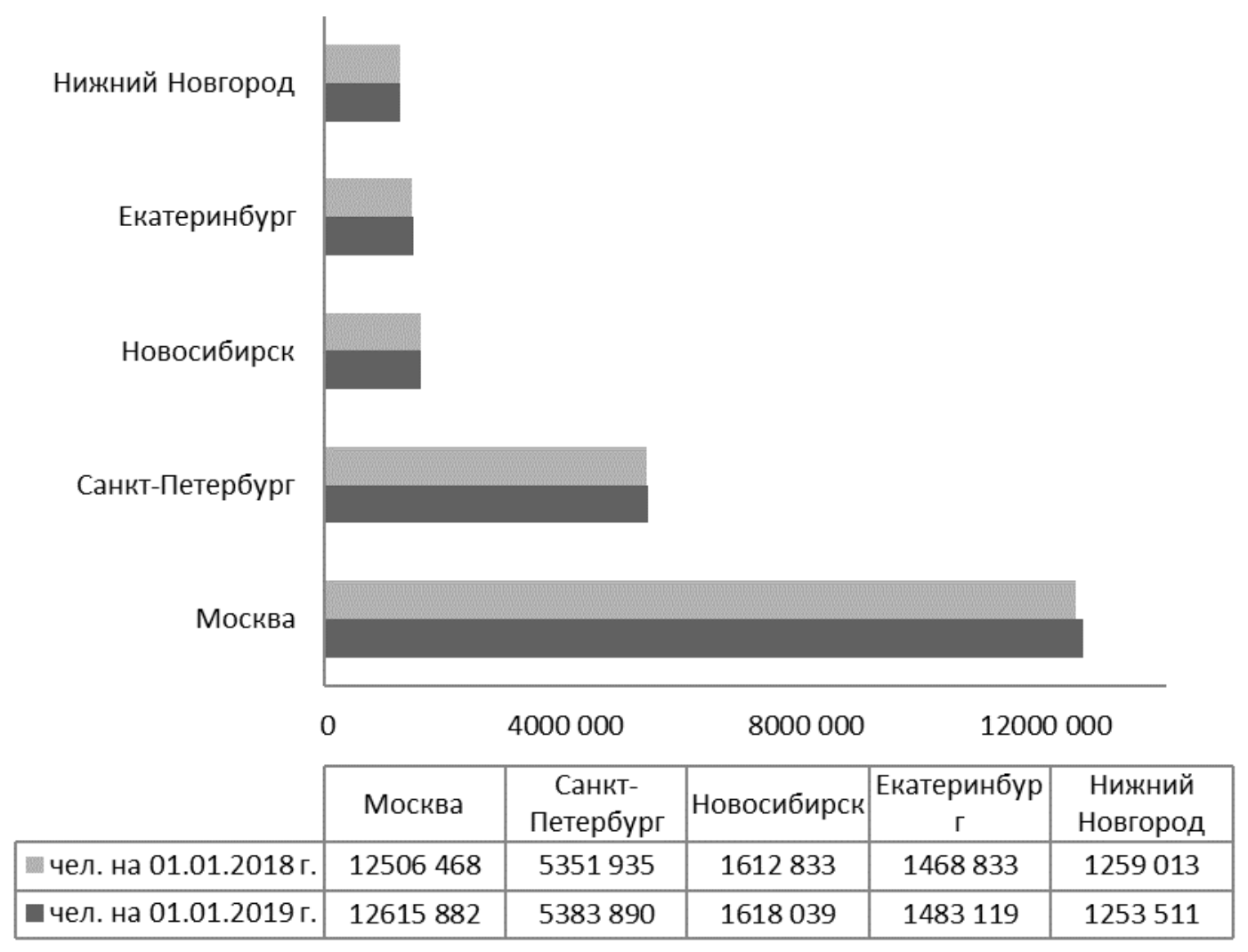

Рис. 2. Распределение численности населения крупных городов в период 2018-2019 гг.

го и муниципального управления. Смарт-технологии способствуют не только повышению эффективности управленческих процессов, но и формированию комфортной безопасной для жизни городской среды. Сегодня численность городского населения значительно превышает численность сельского. А стремительный рост городов, как по площади, так и по числу жителей выдвигает требования внедрения интерактивных технологий в управление городской средой [4].

Инновационный тип управления характеризуется не только стратегированием и инвестированием, но и сетевизацией местных сообществ с использованием программно-целевого метода.

Сетевая форма организации меняет социально-экономическую практику, преобладавшую в социальном пространстве до настоящего времени. Особое значение этот факт имеет в больших городах, где взаимозависимость социальной активности и изменений жизненной среды локальной территории проявляется наиболее ярко. Сетевизация затрагивает общественное пространство, меняет характер взаимодействия власти и граждан в современном городе. Знание особенностей функционирования муниципальной власти в условиях большого города позволит решить многие проблемы территориальной организации населения. [5].

Изношенная транспортная и ЖКХ - инфраструктура нуждается в развитии цифровых возможностей по внедрению интернет-технологий. Чтобы сделать поездки в общественном транспорте комфортнее понадобится внедрение цифровой экосистемы в общественный транспорт и ЖКХ. Одним из прогрессивных и удобных решений современной урбанистики являются технологии сбора данных посредством интернета вещей. Интеллектуализация городов предполагает мониторинг жалоб на городские службы.

Поступательная цифровая трансформация российского общества позволяет решать современные проблемы крупных городов [9]:

- энергосбережение;

- работа транспорта;

- информатизация;

- состояние инфраструктуры;

- благоустройство территории.

Социальные проблемы включают вопросы личной и общественной безопасности, социального и мате- 
риального неравенства, развития местных сообществ и объединение их в сетевые организации, участвующие в решении проблем города. Перечень экологических проблем для каждого города имеет свой так называемый реестр, но такие проблемы как загрязнение воды и воздуха, увеличение уровня шума и количества бытовых отходов свойственны всем городам, независимо от площади территории и числа жителей.

По мнению научно-экспертного сообщества, одним из главных источников, способствующих эффективному преобразованию городских территорий служит социальный потенциал местных сообществ. Вовлекая горожан в совместную деятельность, местные сообщества вселяют в людей веру в собственные возможности и способность изменить жизненную среду города в лучшую сторону. Развитие местных сообществ призвано решить следующие задачи:

- вовлечь жителей городской территории в процесс её развития, трансформируя горожан из субъектов воздействия в субъекты действия;

- накопить у населения способности к совместным с органами муниципальной власти действиям по позитивному влиянию на развитие городской среды и качество жизни в ней;

- мотивировать развитие партнёрства и укреплять готовность к нему между жителями, развивать взаимоуважение, повышать доверие друг к другу;

- воспитать в среде местного сообщества чувство ответственности за территорию своего проживания, за рост уровня социального потенциала.

Чтобы стратегическое планирование по развитию городского пространства и реализация социального потенциала территории были максимально эффективными, необходимо: знать существующие проблемы и причины их обуславливающие, вызывающие неоднозначную реакцию горожан; оценить восприятие населением сложившейся городской среды и общественной жизни [6].

Являясь активными или пассивными участниками городской жизни современные исследователи городского пространства видят все происходящее в нем изменения и возникающие проблемы - изнутри. Обуславливая поведение своих жителей через современные средства коммуникации города предоставляют возможность местному сообществу через интернет и социальные сети оставлять «цифровые следы».

Изучение утверждений жителей на интернет-форумах, содержание репостов, фотографий, лайков даёт возможность исследователям определять предпочтения и потребности городских сообществ, а также оценивать степень согласия или несогласия жителей с управленческими решениями муниципальных властей. Обязательное присутствие органов публичной власти на социальных платформах стало требованием активного поступательного развития в online -пространстве сетевых коммуникаций граждан.

Большинство жителей российских агломераций входят в когорту активных цифровых пользователей социальных сервисов. Поиск информации и общение в социальных сервисах являются основной формой активности [7]. Имея аккаунты на социальных платформах, городские муниципальные образования крупных городов предпочитают создавать паблики «ВКонтакте», «Facebook», «Twitter» и др. Как показывают исследования систем экспертного мониторнга online ресурсов стратегии размещения контента нуждаются в доработке. Отсутствует чёткое определение сегментов целевой аудитории граждан для размещения контента. В результате online пользователи и органы власти не всегда используют контент в инновационной деятельности и решении общественно значимых проблем. Медийное опосредование городской жизни способствует коммуникационной трансформации городских сообществ друг с другом и пространством, создавая локальные городские интернет-сообщества.

С 2017 года в развитие муниципального управления города Москвы внедрен новый тип взаимоотношений власти и граждан, основанных на развитии горизонтальных сетевых взаимодействий. Особенности и проблемы функционирования института муниципального управления в крупных агломерациях обозначили необходимость формирования достойного уровня качества жизни жителей с участием в этом процессе сетевых сообществ граждан локальной территории. К 125 муниципальным районам города Москвы добавилось ещё 21 муниципальное образование, ранее относившиеся по территориальной принадлежности к Московской области. При этом за вновь присоединёнными двумя городскими округами и девятнадцатью поселениями сохранялось право решения довольно обширного круга вопросов местного уровня и широкие права. Для того, чтобы более лояльно осуществить присоединение новых территорий, не ущемляя интересы ни одной из сторон процесса, Правительством Москвы было решено сохранить статус и границы присоединённых территорий. А для «сглаживания» различий в компетенциях началась реализация муниципальной реформы.

Отдельные полномочия органам местного самоуправления предоставлялись:

- в организации работы управы округа и городских организаций;

- в благоустройстве территории; 
- в капитальном ремонте жилищного фонда и содержании его в надлежащем техническом состоянии;

- в определении участков под размещение объектов капитального строительства;

- в разработке плана и утверждении дополнительных мероприятий социального и экономического развития района

Включение различных групп жителей в процесс управления агломерацией и учёт их интересов, является предпосылкой создания устойчивых каналов цифровой коммуникации. Субъектом, контролирующим деятельность муниципальных органов власти и развивающим местное самоуправление, должно быть местное сообщество, объединяемое коммуникативной сетью.

Заслуживающим внимания примером коммуникации общества и власти служит опыт Правительства Мо- сквы. В течение одного года Московское Правительство привлекло к участию в решении городских проблем более чем один миллион граждан - жителей столицы.

Разнонаправленность интересов городских сообществ влечёт неоформленность связей между ними и случайность контактов, оставляя тем самым сетевые сообщества в процессе формирования [8].

Городам нужны комплексные цифровые проекты развития инфраструктуры, федеральный цифровой интегратор городской инфраструктуры. Подводя итог сказанному, необходимо отметить, что успех настоящего этапа реформирования системы муниципального управления крупного города зависит от успешности формирования местных сетевых сообществ, степени их социальной сплочённости, личной ответственности, эмоциональной глубины, устойчивости коммуникации общества и власти.

\section{ЛИТЕРАТУРА}

1. Гуляева 0.А., Мардас А.Н., Мардас Д.А. Математическое моделирование в факторизации рациональной траектории развития производственно-экономической системы Труды международной конференции по мягким вычислениям и измерениям (SCM)/ СПб.: СПбГЭТУ «ЛЭТИ», 2015

2. Ксенофонтова Т.Ю., Мардас А.Н., Гуляева 0.А., Мардас Д.А. В поисках технологических прорывов: почему в России мало успешных стартапов? / В сборнике: Умные технологии в современном мире. Материалы юбилейной всероссийской научно-практической конференции, посвященной 75-летию Южно-Уральского государственного университета. Под редакцией И.А. Баева. 2018

3. Эконометрические методы в стратегическом анализе производственно-экономических систем. / Мардас А.Н., Кадиев И.Г., Гуляева 0.А., Мардас Д.А., СПбГЭТУ, Санкт-Петербург, 2014.

4. Гуляева 0.А., Мардас А.Н., Мардас Д.А. Прогнозная оценка результативности стратегии развития производственно-экономической системы/ СПбГЭтУ, Дискурс. 2016. № 2. С. 79-86

5. Мардас 0.А. Информационное обеспечение автоматизированных систем управления качеством продукции промышленных предприятий /диссертация на соискание ученой степени кандидата технических наук / Северо-Западный открытый технический университет. Санкт-Петербург, 2005.

6. Мардас А.Н., Кадиев И.Г., Гуляева 0.А. Методы стратегического анализа в управлении инвестиционно-инновационной деятельностью в региональных хозяйственных комплексах / монография / Санкт-Петербург, СПбГЭТУ ЛЭТИ, 2011.

7. Ксенофонтова Т.Ю., Мардас А.Н., Гуляева О.А., Чернобай Н.С. Облачные технологии: панацея или маркетинг? В сборнике: Умные технологии В современном мире. Материалы юбилейной всероссийской научно-практической конференции, посвященной 75-летию Южно-Уральского государственного университета. Под редакцией И.А. Баева. 2018.

8. Мардас А.Н., Гуляева 0.А. Теория менеджмента / Учебник / Москва, 2019. Сер.58 Бакалавр. Академический курс (2-е изд., испр. и доп).

9. Bezdudnaya A.G., Ksenofontova T.Y., Rastova Y.I., Kraiukhin G.A., Tulupov A.S. On the issue of the perspective directions of the science-driven production development in Russia / The Journal of Social Sciences Research. 2018. T. 2018. № Special Issue 3. C. 76-80.

10. Ksenofontova T.Y., Bezdudnaya A.G., Smirnov R.V., Prokopenkov S.V., Khomichev E.A., Pashina M.A. Problem analysis, prospects and directions for the development of private entrepreneurship: the regional aspect / Espacios. 2019. T. 40. № 20. C. 29. 